\title{
Fighting Antimicrobial Resistance: Who Should Lead the Agenda?
}

\author{
Wilber Sabiiti* \\ School of Medicine, University of St. Andrews, North Haugh, UK
}

*Corresponding author: Wilber Sabiiti, Senior Research fellow in Medicine, Chair of the TWENDE Consortium, University of St. Andrews, School of Medicine, North

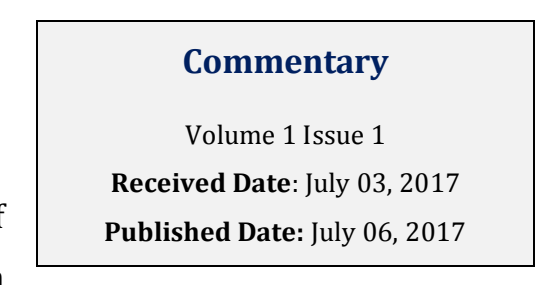

Haugh, St. Andrews, UK, Tel: +44 (0) 1334 463522; E-mail: ws31@st-andrews.ac.uk.

\section{Comment}

The rising level of non-treatable (antimicrobial resistant) bugs has captured global attention. The O'Neill commission warned that failure to act would result in an additional 10 million lives lost each to malaria, HIV, TB, and certain bacterial infections by 2050 , at a cost to the world economy of 100 trillion USD [1]. On 21st Sept 2016, the United Nations (UN) assembly approved the World Health Organisation (WHO) Global action plan (GAP) against antimicrobial resistance (AMR) and urged all member nations to act [2]. However, the contents of the plan and strategies thereof are dominated by what the global north perceives to be the drivers of AMR and consequently how it should be fought. It is crucial that the understanding of AMR and efforts to fight it are contextualised, otherwise the plan will fail to realise its goals. For instance, antibiotic abuse in developed world may be due to overuse of a variety of antibiotics because they are available while in developing world it could be due to overuse of the same class of antibiotics because better antibiotics aren't available.

Nationally-led action against AMR cannot be more critical given the fact that there are huge variations in health systems capacities and the different pressures on the economic purse between developed and developing countries [3]. At the 6th East African health and scientific research conference (28th - 31st March 2017), over 1000 East Africans gathered in Bujumbura, Burundi to discuss and shape the healthcare agenda for the region, the East African Community (EAC). Pertinent to the agenda was drawing action plan to address AMR in the region. A symposium was held that examined the region's antimicrobial agents' usage practices, the AMR burden and made policy recommendations for the EAC action against AMR.
Despite existence of medicines regulations, antimicrobial drugs are still accessible without prescription in the EAC. Most prescriptions occur without following the national guidelines or diagnosis to support the prescription decisions. It is easy to think that this is simply negligence or lack of laboratory capacity but it is not as simple as that. During a prescription behaviour study in one of the EAC countries, a doctor was asked why they prescribe without laboratory diagnosis, he answered, 'the laboratory never returns test results'. When the laboratory manger was asked, they said the clinic never asks for tests. Doctor, the laboratory says you never ask for tests, well, we don't trust the laboratory to deliver the tests. Laboratory manager, why is it that the laboratory is not trusted for performing the required tests, well, the hospital management hardly allocates budget for us to conduct the tests [4]. This back and forth blame game demonstrates that though global, the challenges have a unique local context that must be considered when developing the agenda for action against AMR. Likewise, there are many underlying national and regional factors why regulators (policy enforcers) fail to stop misuse of medicines.

On the human - animal interface, livestock keepers feel neglected by the health system and so have taken matters in their own hands by procuring antimicrobials from open market sales and administering to their animals themselves. For instance, $87-100 \%$ of the Bahima and Basongora pastoralists in western Uganda and $64 \%$ of the Maasai in southern Kenya and northern Tanzania administered antibiotics without consulting Veterinary practitioner [5]. No intervention would be successful without a thorough examination of this behaviour and its impact on the emergence and spread of AMR. In this case, 
a national - community-led agenda is critical. The driving factors are so intricate and require a contextualised response [6]. The answers lie with the communities themselves [3]. In this respect, the symposium was asked to outline the most important aspects they would like to see in the EAC policy on AMR. 107 recommendations were received and grouped into six thematic areas: streamlining health system governance and financing, increasing awareness, strengthening and harmonizing medicines regulatory framework, training, laboratory capacity enhancement, and research and development for new diagnostics, antimicrobials and vaccines. Over $50 \%$ of the recommendations highlighted governance focusing on streamlining to stamp out inefficiency and corruption. Increasing AMR awareness through public and school education was the $2^{\text {nd }}$ popular recommendation. This means dealing with the basics, that is, increasing health system efficiency and educating the masses could solve a large part of the AMR problem without necessarily spending huge sums of money. The agenda for fighting AMR must be led from where the answers are, from the grassroots community to the nations and to the world at large.

\section{Author contribution}

WS: Chaired the Antimicrobial agents' usage, antimicrobial resistance and policy symposium at the 6th East African Health and Scientific Research Conference, 28th - 31st March 2017, Bujumbura, Burundi. He collated, interpreted and contextualized symposium recommendations that form the basis of this comment. Wrote and submitted the recommendations report to the East African Health and Research Commission for incorporation into the East African Community policy on Antimicrobial Resistance.

\section{Acknowledgements}

Co-chair, Helen Meme ${ }^{1} \mathrm{PhD}$; Expert presenters, Benon Asiimwe $^{2} \mathrm{PhD}$ and John Ndemi Kiiru ${ }^{1} \mathrm{PhD}$ for their educative talks on the burden and drivers of antimicrobial resistance in East Africa; Panellists, Henry Kajumbula ${ }^{2}$ MMed, Adam Fimbo ${ }^{3}$ B.Pharm, Amoreen Naluyima ${ }^{4}$ MSc, Emmanuel BAMENYEKANYE5, B.Pharm and Jarred Okoyo Nyakiba ${ }^{6} \mathrm{PhD}$ for contextualising the discussion into the national policy frameworks. Fred Njeleka ${ }^{7}$ BSc for transcribing and digitising the recommendations. TWENDE consortium for sponsoring the symposium and funding from EDCTP, the East African Health Research Commission for hosting the conference and their leadership on AMR policy formulation for the EAC. ${ }^{1}$ Kenya Medical Research Institute, ${ }^{2}$ Makerere University Uganda, ${ }^{3}$ Tanzania Food and Drug Authority, ${ }^{4}$ National Drug Authority Uganda, ${ }^{5}$ Ministry of Health Burundi, ${ }^{6}$ Pharmaceuticals and Poisons Board Kenya, ${ }^{7}$ NIMRMbeya Medical Research Centre.

\section{Funding}

The TWENDE consortium (https://infection.standrews.ac.uk/twende-overview/) is funded by the European and Developing Countries Clinical Trials Partnership (EDCTP). The funder did not participate in writing this comment nor did they influence decision to publish it in the Lancet. The author declares no conflict of interest.

\section{References}

1. O'Neill J (2014) The Review on Antimicrobial Resistance Commission. Antimicrobial Resistance: Tackling a crisis for the health and wealth of nations.

2. PGA Press Releases (2016) General Assembly of the United Nations POT7S. Press Release: High level Meeting on Antimicrobial Resistance 1-5.

3. Mendelson M, Rottingen JA, Gopinathan U, Hamer DH, Wertheim H, et al. (2016) Antimicrobials: access and sustainable effectiveness 3 Maximising access to achieve appropriate human antimicrobial use in low income and middle-income countries. The Lancet 387(10014): 188-198.

4. Kiiru JN (2017) Antimicrobial resistance In East Africa. Trends, Drivers, Challenges and Future Outlooks. Bujumbura 1-32.

5. Asiimwe B (2017) The Human-Animal Interface: Impact on the Use of Antimicrobial Agents and Spread of Antimicrobial Resistance. Bujumbura 119.

6. Holmes AH, Moore LSP, Sundsfjord A (2016) Antimicrobials: access and sustainable effectiveness 2 Understanding the mechanisms and drivers of antimicrobial resistance. The Lancet 387: 176-187. 